\title{
MORPHOLOGICAL VARIATIONS OF THE EGYPTIAN HUMAN LUNGS AND ITS CLINICAL APPLICATIONS
}

\section{Mohammed Ahmed Shehata Amin}

Lecturer of Human Anatomy and Embryology, Faculty of Medicine, Zagazig University, Egypt.

\section{ABSTRACT}

Background:Lung is a vital organ of respiration, Knowledge of the variations in the position and number of fissures and lobes of the lungs is necessary for the appreciation of lobar anatomy and correlate these findings with clinical applications.

Material and Methods: The present study was performed on random lung specimens available at the museum of Human Anatomy and Embryology Department, Faculty of Medicine, Zagazig University, Egypt. A total of 40 lungs (21 right and 19 left) were studied for variations in the fissures, lobes and hilar pattern.

Results: Among the right-sided lungs, $24 \%$ presented with incomplete horizontal fissure, $10 \%$ with absence of the horizontal fissure, $19 \%$ with incomplete oblique fissure and $14 \%$ with accessory fissures. $29 \%$ presented with 2 pulmonary arteries, $38 \%$ with 3 pulmonary veins and $24 \%$ with 3 bronchi in the hilum of right lungs. Among the left-sided lungs, $47 \%$ presented with incomplete oblique fissures, $5 \%$ with absence of the oblique fissure and $16 \%$ with accessory fissures. $16 \%$ of the left lungs showed 2 pulmonary arteries, $37 \%$ had 3 pulmonary veins in the hilum and $21 \%$ had 2 bronchi in the hilum.

Conclusion: The field of lung surgery is now highly advanced, with well developed radiological and endoscopic techniques. Hence, a proper understanding and knowledge of these morphological variations of lung fissures, lobes and the hilar pattern would be beneficial for surgeons, as well as for radiologists.

KEY WORDS:Lung, Lobe, Fissure, Hilum, Pulmonary.

Corresponding Author: Dr. Mohammed Ahmed Shehata Amin, Lecturer of Human Anatomy and Embryology, Faculty of Medicine, Zagazig University, Egypt.

E-Mail:dr.mohammed.shehata2007@gmail.com

Access this Article online

Quick Response code

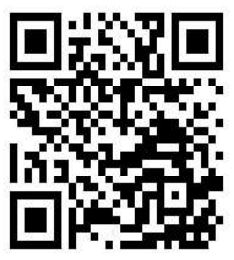

DOI: $10.16965 /$ ijar.2020.187

\begin{tabular}{|c|c|c|}
\hline \multicolumn{3}{|c|}{ Journal Information } \\
\hline \multicolumn{3}{|c|}{$\begin{array}{l}\text { International Journal of Anatomy and Research } \\
\text { RG Journal ISSN (E) 2321-4287 | ISSN (P) 2321-8967 }\end{array}$} \\
\hline \multicolumn{3}{|c|}{ Article Information } \\
\hline $\begin{array}{l}\text { Received: } 11 \text { Jul } 2020 \\
\text { Peer Review: } 11 \text { Jul } 2020 \\
\text { Revised: None }\end{array}$ & $\begin{array}{l}\text { Accepted: } 28 \text { Jul } 2 \\
\text { Published (O): } 10 \\
\text { Published (P): } 10\end{array}$ & 2020 \\
\hline
\end{tabular}

\section{INTRODUCTION}

The lungs are the essential organs of respiration which are located within the thoracic cavity on either side of the heart and other mediastinal structures. Each lung is approximately half a cone in shape. Each lung has an apex, base, three borders and two surfaces. In addition, the right lung is divided into superior, middle and inferior lobes by oblique and horizontal fissures. The left lung is divided into two lobes namely upper and lower by an oblique fissure. The oblique fissure begins from the upper part of the hilum on the mediastinal surface. This fissure cuts the vertebral border at the level of the 4 th or the 5 th thoracic spine, courses along the costal surface, cuts the inferior border and will re-appear on the mediastinal surface and ends at the lower end of the hilum. The horizontal fissure is seen only in the right lung, where it begins at the oblique fissure, courses along the costal surface, cuts the anterior border and appears on the mediastinal surface to end at the hilum [1].

These fissures enable the movement of the 
lobes against each other, thus allowing greater distention and movement of the lower lobes during respiration and, therefore, assisting in a more uniform expansion of the whole lung. The fissures may be complete or incomplete, thus dividing the lungs into complete and incomplete lobes. When the fissures are complete, the lobes are held together only at the hilum by the bronchi and pulmonary vessels, or they may be incomplete when there are areas of parenchymal fusion between the lobes, or, they may be absent altogether [2].

Each lung shows a triangular depression behind the cardiac impression in the mediastinal surface named the hilum, where the structures which form the root of the lung enter and leave the organ. Both the lungs contain two pulmonary veins and one pulmonary artery through the hilum. The bronchi differ in their mode of subdivision between the left and right lungs. The right bronchus gives off a branch to the superior lobe about $2.5 \mathrm{~cm}$ from the bifurcation of the trachea. As this branch arises above the level of the pulmonary artery it is named as the eparterial bronchus. Other division come off below the artery and thus termed hyparterial bronchus. The left bronchus passes below the level of pulmonary artery before it divides and so all its branches are considered hyparterial [1].

The knowledge of variations in the lung fissures, lobes and hilar pattern is of clinical importance for the cardiothoracic surgeons while performing the segmental resection of the infected bronchopulmonary segments. Also, this knowledge is extremely important for the radiologists in interpreting the radiological images and is also of academic interest [3].So the Aim of the Work was to put a spot light on the variations in the position and number of fissures, lobes and hilar pattern of the lungs and correlate these findings with clinical applications.

Statistical analysis: All data were tabulated and statistically analyzed by using Statistical Package for the Social Science (version 15) software (SPSS).

\section{MATERIAL AND METHODS}

The present study was performed on intact lung specimens with good condition available at the museum of Human Anatomy and Embryology Department, Faculty of Medicine, Zagazig University, Egypt. A total of 40 lungs (21 right and 19 left) were used in the study. The study was done on well performed jars with good specimens. Diseased, mutilated and injured specimens were excluded from the beginning of study. The lungs were removed from cadavers preserved in $10 \%$ formalin, which were utilized for routine dissection, during the course of undergraduate and postgraduate medical training. The age and gender difference of the lungs were not determined in the study.The study was approved by the research ethical committee of Faculty of Medicine, Zagazig University. The following parameters were noted in the current study: the number of fissures and lobes, the presence of any variant fissure as well as the variations in the hilar structures.

\section{RESULTS}

Right lungs: Among the 21 right lungs, 2 lungs (10\%) showed absence of horizontal fissures (AHF) (Fig.1) and 5 lungs (24\%) showed incomplete horizontal fissures (IHF) (Fig.2).4 lungs (19\%) showed incomplete oblique fissures (IOF) (Fig.1), 3 lungs (14\%) showed accessory fissures (AF) (Fig.3).6 lungs (29\%) had 2 pulmonary arteries (PA) (Fig.4), 15 lungs (71\%) had 1 (PA) in the hilum(Fig.5).8 lungs (38\%) had 3 pulmonary veins (PV) (Fig.4), while 13 lungs (62\%) had 2 (PV) in the hilum(Fig.5).5 lungs (24\%) showed 3bronchi (B) (Fig.5), where as 16 lungs (76\%) showed 2 (B) in the hilum(Fig.4). All the variations seen in the right lungs are collected and tabulated in table (1).

Left lungs: Among the 19 left lungs, 1 lung (5\%) showed absence of oblique fissure (Fig.6), 9 lungs (47\%) showed incomplete oblique fissures (IOF) (Fig.7) and 3 lungs (16\%) showed accessory fissures (AF) (Fig.8). 3 lungs (16\%) had 2 pulmonary arteries (PA) (Fig.9), 16 lungs (84\%) had 1 (PA) in the hilum (Fig.10). 7 lungs (37\%) had 3 pulmonary veins (PV) (Fig.10), while 12 lungs (63\%) had 2 (PV) in the hilum(Fig.9). 4 lungs (21\%) showed 2 (B) in the hilum(Fig.9), where as 15 lungs (79\%) showed 1 (B) in the hilum(Fig.10). All the variations seen in the left lungs are collected and tabulated in table (2). 


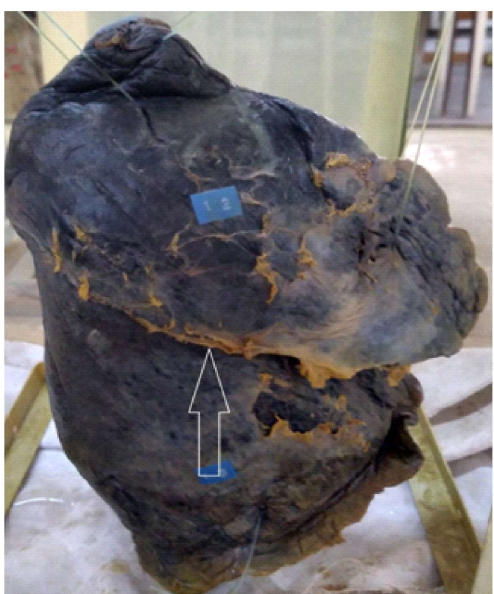

Fig. 1: Right lung with two lobes and one fissure showing absence of horizontal fissure and incomplete oblique fissure (arrow).

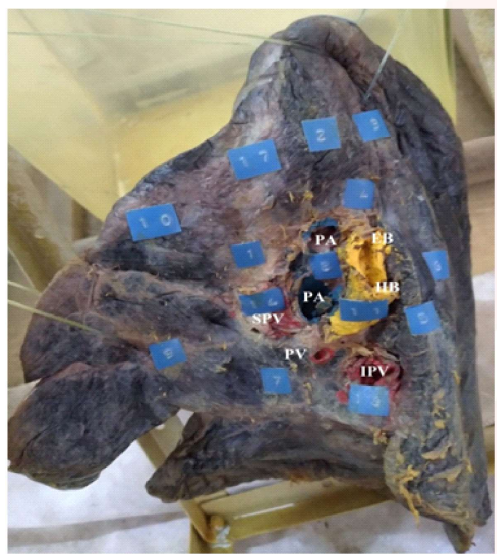

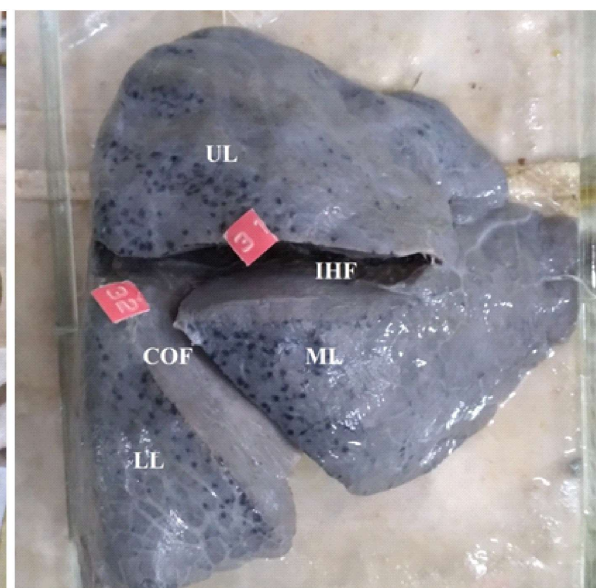

Fig. 2:Right lung divided by incomplete horizontal fissure (IHF) and complete oblique fissure (COF) into 3 lobes; upper lobe (UL), middle lobe (ML) and lower lobe (LL).

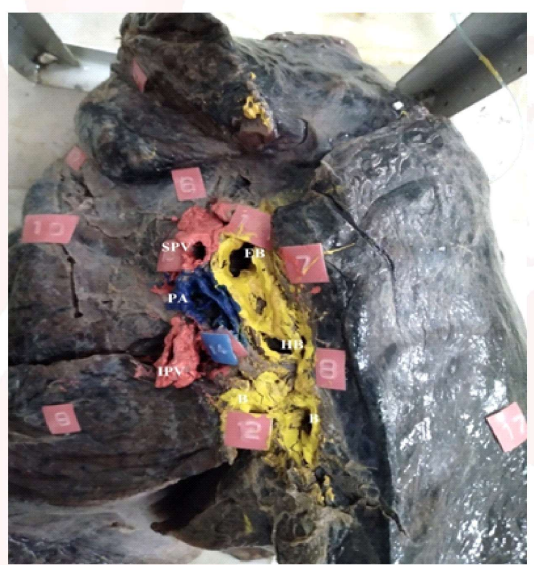

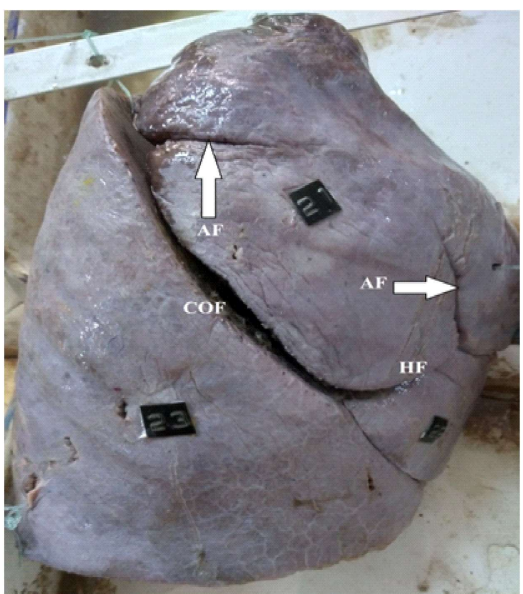

Fig. 3:Right lung showing horizontal fissure (HF), complete oblique fissure (COF) and 2 other accessory fissures (AF).

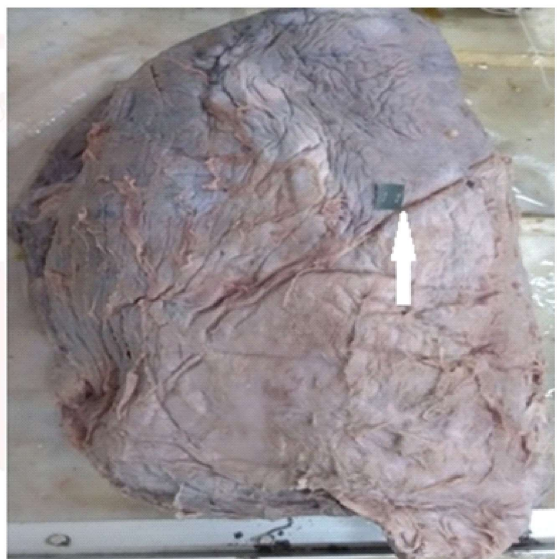

Fig. 4: Mediastinal surface of the Fig. 5: Mediastinal surface of the right right lung showing a hilum lung showing a hilum containing 3 containing 2 bronchi, eparterial bronchi, eparterial bronchus (EB) ,hyparbronchus (EB) and hyparterial terial bronchus (HB) and another bronbronchus (HB), 2 pulmonary chus (B) at the lower part of the hilum, 1 arteries (PA) and 3 pulmonary pulmonary artery (PA) and 2 pulmonary veins (PV). veins (PV) (superior and inferior).
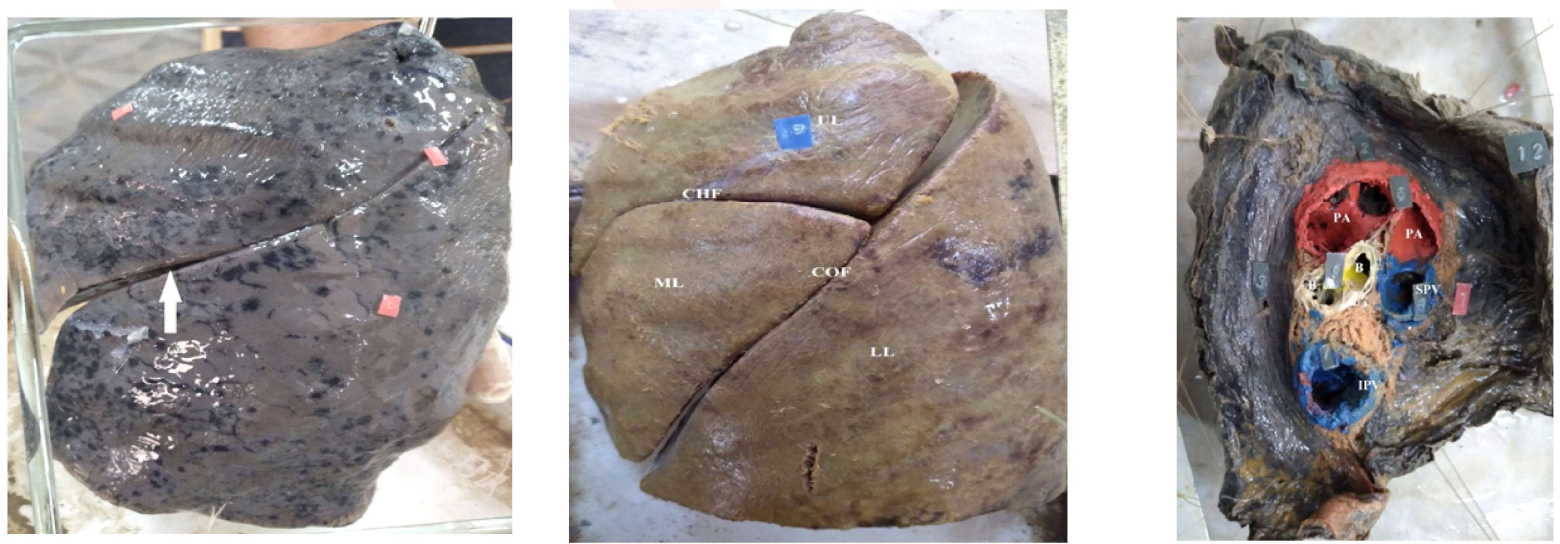

Fig. 8: Left lung divided by complete oblique Fig. 9:Mediastinal surface of the fissure (COF) and complete horizontal left lung showing a hilum fissure (CHF) as an accessory fissure into containing 2 bronchi (B), 2 3 lobes; upper lobe (UL), middle lobe (ML) pulmonary arteries (PA) and 2 and lower lobe (LL). pulmonary veins (PV) (superior and inferior). 


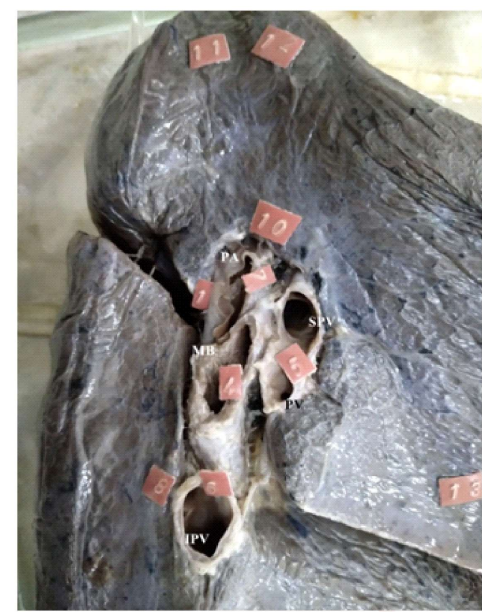

Fig. 10: Mediastinal surface of the left lung showing a hilum containing 1 main bronchus (MB), 1 pulmonary artery (PA) and 3 pulmonary veins (PV).

N.B: All the numbers and the colored structures in the hilum of the lungs were previously made by the anatomists in the Human Anatomy and Embryology Department, Faculty of Medicine, Zagazig University, Egypt.

Table 1:The variations seen in the right lungs.

\begin{tabular}{|lcc|}
\hline \multicolumn{1}{|c|}{ Right Lung (total number=21) } & & \\
\hline \multicolumn{1}{c}{ Feature } & Number & Percentage \\
\hline Incomplete oblique fissure & 4 & $19 \%$ \\
\hline Incomplete horizontal fissure & 5 & $24 \%$ \\
\hline Absence of horizontal fissure & 2 & $10 \%$ \\
\hline Accessory fissure & 3 & $14 \%$ \\
\hline Two pulmonary arteries in the hilum & 6 & $29 \%$ \\
\hline One pulmonary artery in hilum & 15 & $71 \%$ \\
\hline Three pulmonary veins in the hilum & 8 & $38 \%$ \\
\hline Two pulmonary veins in the hilum & 13 & $62 \%$ \\
\hline Three bronchi in the hilum & 5 & $24 \%$ \\
\hline Two bronchi in hilum & 16 & $76 \%$ \\
\hline
\end{tabular}

Table 2:The variations seen in the left lungs.

\begin{tabular}{lcc|}
\hline \multicolumn{1}{|c|}{ Left Lung (total number=19) } & & \\
\hline \multicolumn{1}{c}{ Feature } & Number & Percentage \\
\hline Incomplete oblique fissure & 9 & $47 \%$ \\
\hline Absence of oblique fissure & 1 & $5 \%$ \\
\hline Accessory fissure & 3 & $16 \%$ \\
\hline Two pulmonary arteries in the hilum & 3 & $16 \%$ \\
\hline One pulmonary artery in hilum & 16 & $84 \%$ \\
\hline Three pulmonary veins in the hilum & 7 & $37 \%$ \\
\hline Two pulmonary veins in the hilum & 12 & $63 \%$ \\
\hline Two bronchi in the hilum & 4 & $21 \%$ \\
\hline One bronchus in hilum & 15 & $79 \%$ \\
\hline
\end{tabular}

\section{DISCUSSION}

The lungs develop from the respiratory diverticulum of cranial foregut as early as the 4th week of gestation which subsequently differentiates into the various components of the respiratory tree and parenchyma. With progressive development, all the spaces between individual segments get obliterated except along the lines of division of principal bronchi, where deep complete fissure remains patent dividing the right lung into three lobes and the left lung into two lobes. The fissures are oblique and horizontal in position in the right lung and only one fissure is placed obliquely in the left lung. Absence or incompleteness of fissures could be due to obliteration of these fissures either completely or partially and accessory fissures could be the result of non obliteration of spaces which are normally obliterated [4]. With defect in lung development, there can be variation in the lobes and fissures of lungs [5]. Along these fissures the visceral pleura is reflected and covers the individual lobes on all sides. The monopodial branching of stem bronchi accounts for accessory bronchi and lobes often found in adult lung [6].

The present study showed that, in majority of specimens the oblique fissures were incomplete, more on the left side (47\%) than on the right $(19 \%)$. The increased incidence of incomplete oblique fissures on the left side might indicate early commencement of fusion of the prenatal fissures which may proceed further before birth, leading to fusion along floor of the oblique fissure [7].This was in contrary to what (Bergmann et al) [8] said as they found the incidence of incomplete oblique fissures to be similar in both lungs (30\%).

In the present study incomplete horizontal fissure was seen in $(24 \%)$ of right sided lungs which was comparable with the results of the study done by (Prakash, et al)(50\%) [9]. In addition, the present study demonstrated one lung specimen with absent oblique fissure. This comes in accordance with what [9] found. In addition, [10] reported absence of oblique fissure in $2 \%$ of right and $5 \%$ of left lung. The presence of fissures in normal lung enhances uniform expansion, and their position could be used as reliable landmarks in specifying lesions within the thorax, in general, and within the lungs in particular [11]. Pneumonia in a particular lobe is contained within the confines of the lobe by complete fissures. In patients with incomplete fissures, pneumonia may spread to adjacent lobes through the parenchymal continuation [12]. 
Also, in the present study accessory fissures were observed in both lungs. These Accessory fissures are commonly observed in lung specimens, but are often unappreciated or misinterpreted on radiographs and CT scans. They can be mistakenly confused with areas of linear atelectasis, pleural scars, or walls of bullae. In the present work, one specimen of the left lung showed an accessory fissure, which divided it into 3 lobes instead of 2 lobes. Some of the previous studies also report the presence of accessory lobes of lungs as mentioned by [13]. An accessory fissure might alter the usual pattern of lung collapse causing difficulty in diagnosing a lesion and its extent. The wide range of difference in the occurrence of horizontal, oblique and accessory fissures between and among different populations may be due to a variety of genetic and environmental factors [14].

From studies of different authors, knowledge of fissural anatomy explains various radiological appearances of interlobar fluid. Post-operative air leakage is due to an incomplete fissure [15]. The accessory fissure might act as a barrier to spread in the tissue creating a sharply demarcated pneumonia, which could be misinterpreted as atelectasis or consolidation. Segmental localization is a must for a thoracic surgeon and knowledge of accessory fissures is of great significance to cardiothoracic surgeons for planning segmental resections or pulmonary lobectomies [16].

Also, in the present study the hilum of right lung showed anatomical variations in the form of presence of 2 pulmonary arteries (PA) representing (29\%), 3 bronchi (B) (24\%) and 3 pulmonary veins (PV) (38\%). These results were in disagreement with (George et al) [17] who stated that the percentage of 2 (PA) was (67.69\%), 3 (B) (1.53\%) and 3 (PV) (32.30\%). Similar variations were also reported by (Jacob et al) [18] who observed that the percentage of 2 (PA) was (33\%), 3 (B) (9\%) and 3 (PV) (56\%). While the hilum of left lung in the present study showed anatomical variations in the form of presence of 2 pulmonary arteries (PA) representing (16\%), 2 bronchi (B) (21\%) and 3 pulmonary veins (PV) (37\%). The incidence of these variations was close to what mentioned by [17] and [18].
Recommendations: From the anatomical point of view, Clinicians must be aware of the frequency of variations in the pattern of lobes, fissures and hilar structures of the lungs in order to avoid and reduce the mortality and morbidity associated with invasive procedures. A radiologist must be warranted towards the depth and occurrence of these variations in order to prevent and avoid the misinterpretation of the radiological images.

\section{CONCLUSION}

Knowledge of the anatomical variations of the lung fissures and lobes are important to plan various surgical procedures in order to avoid post-operative complications like air leakage. It can also help to explain various radiological imaging of lobar anatomy of the lungs and the position of the interlobar fluid. Also the present study shows different variations that can occur at the hilar structures of the human lungs. Prior anatomical knowledge and suspicion for probable variations may be crucial for clinicians, cardiothoracic surgeons and radiologists.

\section{ACKNOWLEDGEMENTS}

The author wish to thank Mr. Mohammed Abd El Menem, the gross anatomy technician, and all the other supporting staff of the Human Anatomy and Embryology Department, Faculty of Medicine, Zagazig University for their help at various stages of the study.

\section{ABBREVIATIONS}

AHF -Absence of Horizontal Fissures.

IHF -Incomplete Horizontal Fissures.

IOF -Incomplete Oblique Fissures.

AFs -Accessory Fissures.

Pas - Pulmonary Arteries.

PVs - Pulmonary Veins.

B - Bronchi.

COF - Complete Oblique Fissures.

EB -Eparterial Bronchus.

HB -Hyparterial Bronchus.

UL - Upper Lobe.

ML - Middle Lobe.

LL - Lower Lobe.

MB -Main Bronchus. 


\section{Conflicts of Interests: None}

\section{REFERENCES}

[1]. Standring, S. Gray's Anatomy. The Anatomical Basis of Clinical Practice, $41^{\text {th }}$ Ed, Elsevier Churchill Livingstone, London, 2015;926-930.

[2]. Rosse, C.; Gaddum and Rosse, P. Textbook of Anatomy. $5^{\text {th }}$ ed. Philadelphia: Lipincott-Raven; 1997:441-461.

[3]. Meenakshi, S, Manjunath, KY, Balasubramanyam V. Morphological variations of the lung fissures and lobes. Indian J Chest Dis Allied Sci 2004;46:179182.

[4]. Sadler, TW. Langman's medical embryology. Lippin cott Williams and Wilkins, Baltimox Maryland; 9th ed. 2004:223-284.

[5]. Nisha K,Vishram, S,Rucira S, Vinod K. Anomalous fissures and lobes of human lungs of North Indian population of Western U.P. J Anat Soc India 2014; 63:26-30.

[6]. Cronin P, Gross BH, Kelly AM, Patel S, Kazerooni EA, Carlos RC. Normal and accessory fissures of the lung-evaluation with contiguous volumetric thin section multi detector CT. European journal of Radiology.2010;75(2):8.

[7]. Dutta S, Mandal L, Mandal SK, Biswas J, Ray A,Bandopad-hyay M. Natural fissures of lung- anatomical basis of surgi-cal techniques and imaging. Nat J Med Res. 2013; 3(2): 117-121.

[8]. Bergman RA, Afifi AK, Miyauchi R. Variations of the lobes and fissures of lungs. In: Illustrated Encyclopedia of Human Anatomic Variations: Opus IV: Organ Systems: Respiratory System. http:// www.anatomyatlases.org/AnatomicVar iants/ OrganSystem/Text/LungsTrachea.shtml. Accessed on 7th April 2012.

[9]. Prakash, Bhardwaj AK,Sashirekha M, Suma HY, Gowtham Krishna G, Singh G. Lung Morphology: a cadaveric study in Indian Population. Ital J AnatEmbryol. 2010; 115(3): 235- 240.
[10]. Ghosh, E,Basu R,Dhur A, Roy A, Roy H, Biswas, A. Variations of fissures and lobes in human lungs: a multicentric cadaveric study from West Bengal, India. Int J AnatRadiol Surg 2013;2:5-8.

[11]. MagadumA, DixitD,Bhimallis. Fissures and lobes of lung - an anatomical study and its clinical significance. Int J Cur Res Rev. 2015; 7(3): 8-12.

[12]. Tarver RD. How common are incomplete pulmonary fissures, and what is their clinical significance? ARJ Am J Roentgenol. 1995; 164:761.

[13]. Esomonu UG, Taura MG,Modibbo MH,Egwu AO. Variation in the lobar pattern of the right and left lungs: A case report. Australas Med J 2013; 6:511514.

[14]. Godwin, JD, Tarver RD. Accessory fissures of the lung. Am J Roentgenol. 1985;144:39-47.

[15]. Ariyurek OM,Gulsun M,Demirkazik FB. Accessory fissures of the lung-evaluation by high resolution computed tomography.European journal of Radiology. 2001;11(12):2449-2453.

[16]. Frija J,Naajib J, David M,Hacein B, Laval JM. Incomplete and accessory pulmonary fissures studied by high resolution $x$-ray computed tomography. Journal of Radiology.1988 Mar; 69(3): 163-170.

[17]. George BM, Nayak SB,Marpalli S. Morphological variations of the lungs: a study conducted on Indian cadavers. Anat Cell Biol 2014;47(04):253-258.

[18]. Jacob SM,Venniyoor V, Pillay M. Variations in the Morphology of Human Lungs and its Clinical Implications. J Morphol Sci 2019;36:231-236.

How to cite this article: Mohammed Ahmed Shehata Amin. MORPHOLOGICAL VARIATIONS OF THE EGYPTIAN HUMAN LUNGS AND ITS CLINICAL APPLICATIONS. Int J Anat Res 2020;8(3.2):7674-7679. DOI: 10.16965/ijar.2020.187 